\title{
A comparison of the treatment effects of the Forsus Fatigue Resistance Device and the Twin Block appliance in patients with class II malocclusions
}

\author{
This article was published in the following Dove Press journal: \\ Clinical, Cosmetic and Investigational Dentistry \\ 2 August 2014 \\ Number of times this article has been viewed
}

\author{
Abdulfatah Hanoun' \\ Thikriat S Al-Jewair ${ }^{1,2}$ \\ Sawsan Tabbaa' \\ Mhd Amer Allaymouni' \\ Charles B Preston' \\ 'Department of Orthodontics, \\ School of Dental Medicine, \\ State University of New York at \\ Buffalo, NY, USA; ${ }^{2}$ College of \\ Dentistry, University of Dammam, \\ Saudi Arabia
}

\begin{abstract}
Objectives: We evaluated the skeletal and dentoalveolar effects of the Forsus Fatigue Resistance Device (FRD) and the Twin Block appliance (TB) in comparison with nontreated controls in the treatment of patients with class II division 1 malocclusion.

Materials and methods: This retrospective study included three groups: TB $(n=37$; mean age, 11.2 years), FRD ( $n=30$; mean age, 12.9 years), and controls ( $n=25$; mean age, 12.6 years). Lateral cephalograms were evaluated at T1 (pretreatment) and at T2 (postappliance removal/ equivalent time frame in controls). Cephalometric changes were evaluated using the Clark analysis, including 27 measurements.

Results: Sagittal correction of class II malocclusion appeared to be mainly achieved by dentoalveolar changes in the FRD group. The TB was able to induce both skeletal and dentoalveolar changes. A favorable influence on facial convexity was achieved by both groups. Significant upper incisor retroclination occurred with the TB $\left(-12.42^{\circ}\right)$, whereas only $-4^{\circ}$ was observed in the FRD group. The lower incisors proclined more in the FRD group than the TB group. Incisor overjet reduction was $62 \%$ in the TB group versus $56 \%$ in the FRD group. Molar relation was corrected in both functional groups, resulting in a class I relation, although no change appeared in the control sample.

Conclusion: Both appliances were effective in correcting the class II malocclusion. Both the FRD and the TB induced significant maxillary and mandibular dentoalveolar changes; skeletal changes were induced by TB but not FRD therapy.
\end{abstract}

Keywords: orthodontics, cephalometry, class II malocclusion, functional appliances

\section{Introduction}

Class II malocclusions are of interest to practicing orthodontists because they constitute a significant percentage of the cases they treat. ${ }^{1}$ Myriad treatment modalities for class II malocclusions have been investigated and published. ${ }^{2}$ Some authors attempt to correct the underlying skeletal imbalance through growth modification by either extraoral traction or functional appliances, whereas others focus on dental camouflage of the jaw discrepancy.

The Twin Block (TB; Clark, 1982) appliance is one of the widely used removable functional appliances to correct class II dentoskeletal disharmony. It was found to be the preferred functional appliance in the United Kingdom; more than 75\% of British Orthodontic Society members claimed it is their first choice. ${ }^{3}$ One of the unique features of this appliance is that it is constructed in two separate parts: the upper and
Correspondence: Thikriat S Al-Jewair Department of Orthodontics, School of Dental Medicine, State University of New York at Buffalo, 3435 Main Street Buffalo, New York 14214, USA

$\mathrm{Tel}+\mathrm{I}$ 7I67134547

Email taljewair@gmail.com 
lower appliances. Forward mandibular posturing is achieved by incorporating buccal blocks with interlocking inclined planes of approximately $70^{\circ}$, with the lower blocks engaging in front of the upper blocks. ${ }^{4-6}$

The effects of the TB are well established in the literature..$^{4,5,7}$ O'Brien et $\mathrm{al}^{8}$ investigated the changes in the anteroposterior relationship of the maxilla to the mandible and the overjet during treatment for growing patients (8-10 years). The mean overjet correction was $6.6 \mathrm{~mm}$, whereas the net effect of treatment in terms of overjet correction when compared with the untreated group was $6.9 \mathrm{~mm}$. The skeletal contribution to the overjet correction was $27 \%$; the remaining $73 \%$ was a result of dentoalveolar changes.

The TB, however, is highly dependent on patient compliance. To overcome this limitation, a new generation of fixed functional appliances has become popular. These appliances are more streamlined than the removable types and do not interfere with speech. The Herbst appliance ${ }^{2}$ and its different modification was one of the early compliancefree appliances. Recently, the idea of incorporating nickeltitanium push coil springs as part of the appliances has received a lot of interest. These appliances include Saif Spring, ${ }^{9}$ Jasper-Jumper, ${ }^{9}$ Klapper spring, ${ }^{9}$ Eureka Spring appliance, ${ }^{10}$ the Adjustable Bite Corrector, ${ }^{11}$ and Xbow. ${ }^{12}$ The more advanced and recently popularized designs include the Twin Force bite corrector ${ }^{13}$ and the Forsus Fatigue Resistant Device (FRD). ${ }^{14-16}$

The FRD (3M Unitek Corp, Monrovia, CA, USA) is a semirigid telescoping system incorporating a superelastic nickel-titanium coil spring that can be assembled chair-side and that can be used in conjunction with complete fixed orthodontic appliances. The FRD attaches at the maxillary first molar and onto the mandibular archwire, distal to either the canine or the first premolar bracket.

Many papers were published on the FRD, but only a few were clinical studies ${ }^{15-19}$ reporting variable effects. Franchi et $\mathrm{al}^{16}$ found that the FRD protocol is effective in correcting class II malocclusion with a combination of skeletal and dentoalveolar modifications, although a recent cephalometric study $^{20}$ of class II correction with the Sabbagh Universal Spring and the FRD found that both appliances did not induce significant skeletal effects. The correction was mainly dentoalveolar, with more mandibular incisors proclination in the FRD than with the Sabbagh Universal Spring².

The objective of this study was to evaluate the dentoskeletal changes with FRD and TB in class II patients in comparison with untreated controls.

\section{Materials and methods}

This is a retrospective comparative study of class II malocclusion subjects treated with TB or FRD in comparison with a matched sample of untreated class II controls.

A total of 92 patients were included: 30 in the FRD group (12 girls and 18 boys; mean \pm SD of 12.9 \pm 1.1 years), obtained from one private practice, and 37 in the TB group (24 girls and 13 boys; 11.2 \pm 1.6 years), selected from the private practice of the developer of the appliance, Dr William Clark (Scotland, United Kingdom). This TB sample was previously used in other studies to investigate the TB therapy effects $;{ }^{6} 25$ untreated class II subjects (12 girls and 13 boys; $11.9 \pm 1.9$ years) obtained from the University of Michigan growth study and matched with the experimental groups for skeletal age (at the start or during the growth spurt), sex, and craniofacial morphology. This study was approved by the State University of New York at Buffalo Institutional Review Board.

The inclusion criteria were: Caucasian healthy boys and girls who were starting or within the period of their skeletal growth spurt, as indicated by the cervical vertebral maturation method; class II division 1 malocclusion, with the canines and molars in at least an end-to-end relationship; in the late mixed or early permanent dentitions; normal growth pattern (Frankfort to Mandibular plane angle $=21^{\circ}-35^{\circ}$ ); A point-Nasion-B point angle $\geq 4.5^{\circ}$; retrognathic mandible (Sella-Nasion-B point angle $\leq 76^{\circ}$, Sella-Nasion-A point angle $\geq 80^{\circ}$ ); records of sufficient quality for accurate identification of landmarks on cephalograms; exclusive treatment with FRD or TB for at least 6 months; having the appliance not removed prematurely because of breakage; and nonextraction treatment. Patients with unfavorable growth patterns, craniofacial anomalies, in the early mixed dentition, or who had an anterior open bite of more than $2 \mathrm{~mm}$ were all excluded.

The TB sample received the original design and treatment protocol suggested by Dr Clark. ${ }^{6}$ No brackets were bonded during the TB therapy. The bite registration was taken by advancing the mandible sagittally, with no deviation, by $7 \mathrm{~mm}$, with 3-5 mm interocclusal clearance in the first bicuspid region. The treatment continued until the molars achieved a solid Angle's class I occlusion. Although the FRD sample received the clip-on design, before FRD insertion, the maxillary and mandibular arches were bonded with preadjusted edgewise appliances (0.022-inch bracket slot) until the upper and lower $19 \times 25$-inch SS wires were reached. The mandibular archwire was cinched distal to the molars. For the maxillary dentition, the archwire management varied according to the individual treatment goals in terms of upper 
molar distalization. Then the FRD was attached distal to the mandibular first bicuspids. The bracket torques were $17^{\circ}$ and $10^{\circ}$ in the maxillary central and lateral incisors and $-6^{\circ}$ in the mandibular incisors.

\section{Cephalometric analysis}

Two lateral cephalograms for each subject were used, pretreatment, with the functional appliances (T1), immediately before the insertion of the FRD appliance in fully bonded upper and lower arches, and before any treatment in the TB group, and with postfunctional appliance removal (T2). Clark cephalometric analysis was used, which includes 27 angular and linear measurements. ${ }^{6}$ Nine randomly selected radiographs were digitally retraced and remeasured 3 weeks apart by a single evaluator. An intraclass correlation coefficient was used to evaluate intraobserver reliability, and the Dahlberg formula was used to calculate the random method error.

One investigator who was blind to the type of group digitally traced and analyzed the cephalograms of the FRD and the controls, using the Dolphin system (Dolphin Digital Imaging System, version 11; Chatsworth, CA, USA). Dr Clark, using Quick Ceph ${ }^{\mathrm{TM}}$ (Quick Ceph Systems; San Diego CA, USA), traced the TB sample, and the intraexaminer reliability was reported in a previous study. ${ }^{6}$ The magnification for the radiographs was standardized at $8 \%$. Craniofacial superimpositions were made using $\mathrm{S}-\mathrm{N}$ reference line and registered at Sella. Maxillary superimpositions were made along the palatal plane, registered at an A point-Nasion-B point angle, whereas the mandibular superimpositions were made on the inner contour of the inferior symphysis, the inferior mandibular canal, and the germ of the third molar, if present. Maxillary and mandibular dentoalveolar changes were evaluated using reference lines perpendicular on the palatal plane and mandibular plane, respectively. All superimpositions were conducted manually.

\section{Data analyses}

The data were analyzed using SPSS software (version 21; IBM Corporation, Armonk, NY, USA). Descriptive statistics were used to present the baseline data of each of the three groups. The Levene test was used to check for the homogeneity of variances at T1 of all three groups. Paired $t$-tests were used to compare pre- and posttreatment measurements in each group. Analysis of variance (ANOVA) was used to compare the mean changes between the three groups, followed by Tukey HSD (honestly significant differences) for determining homogeneous subsets whenever appropriate. The significance level was set at $5 \%$.

\section{Results}

The results were obtained from an evaluation of 184 lateral cephalograms of 92 subjects. Each subject was evaluated at $\mathrm{T} 1$ and T2. The mean ages at T1 and treatment/observation periods are presented in Table 1 .

The results of the reliability testing between the repeated measurements revealed good agreement $(r=0.83-0.99)$. Dahlberg's variance results showed that the random method error was within $1 \mathrm{~mm} / 1^{\circ}$.

The sex distribution between the three groups did not show statistically significant differences. Although there were more men than women in the FRD group, this $20 \%$ difference did not achieve statistical significance $(P=0.36)$.

Overall, the groups were comparable at baseline (T1) with the exception of; the incisor overjet, the posterior facial height, the mandibular length, and the ramus height, which showed significant differences between the treatment groups and the untreated controls.

\section{Within-group comparisons}

Significant skeletal changes were observed at T2 in all three groups (Table 2). Posterior facial height increased by $2.7 \pm 2 \mathrm{~mm}$ in the control group, $3.2 \pm 2.4 \mathrm{~mm}$ in the TB, and $1.6 \pm 1.4 \mathrm{~mm}$ in the FRD. The mean total mandibular length significantly increased by $3.13 \pm 2.7 \mathrm{~mm}$ in the controls, $6.3 \pm 3.9 \mathrm{~mm}$ in the TB, and $1.6 \pm 2.1 \mathrm{~mm}$ in the FRD. A similar finding was noted for the ramus height (mean increase of $2.3 \pm 1.8 \mathrm{~mm}$ in controls, $4.2 \pm 2.5 \mathrm{~mm}$ in $\mathrm{TB}$, and $1.3 \pm 1.3 \mathrm{~mm}$ in FRD).

The dentoalveolar changes were much more notable than the skeletal changes. The upper incisors retroclined significantly in the TB $\left(12.4^{\circ} \pm 6.5^{\circ}\right)$ and FRD $\left(3.9^{\circ} \pm 4.5^{\circ}\right)$ groups, with no significant change in the controls. The mandibular incisors flared by $2.1^{\circ} \pm 5.7^{\circ}$ in the TB and by $3.9^{\circ} \pm 4.6^{\circ}$ in the FRD groups, respectively. The mean decrease in the overjet was $62 \%$ in the TB and $56 \%$ in the FRD groups, respectively.

Table I Age and treatment/observation times of the experimental and control groups

\begin{tabular}{lll}
\hline Group & $\begin{array}{l}\text { Mean age (years) } \\
\pm \text { standard } \\
\text { deviation (TI) }\end{array}$ & $\begin{array}{l}\text { Mean treatment/ } \\
\text { observation time } \\
\text { (years) } \pm \text { standard } \\
\text { deviation (TI-T2) }\end{array}$ \\
\hline $\begin{array}{l}\text { Twin Block } \\
\text { Forsus Fatigue }\end{array}$ & $11.2 \pm 1.6$ & $\mathrm{I} .3 \pm 0.6$ \\
$\begin{array}{l}\text { Resistance Device } \\
\text { Control }\end{array}$ & $12.9 \pm 1.2$ & $0.7 \pm 0.1$ \\
\hline
\end{tabular}

Notes: TI: immediately before the insertion of the FRD appliance in fully bonded upper and lower arches, and before any treatment in the TB group. T2: postfunctiona appliance removal. 
Table 2 Within-group comparisons of changes between TI and T2

\begin{tabular}{|c|c|c|c|c|c|c|c|c|c|}
\hline \multirow[t]{2}{*}{ Variable } & \multicolumn{3}{|c|}{ Mean (TI-T2) } & \multicolumn{3}{|c|}{ SD (TI-T2) } & \multicolumn{3}{|c|}{$P$-value* } \\
\hline & CRT & TB & FRD & CRT & TB & FRD & CRT & TB & FRD \\
\hline Cranial base, $^{\circ}$ & -0.44 & -0.29 & -0.35 & 0.67 & 1.47 & 0.53 & $0.00 *$ & 0.23 & $0.00 *$ \\
\hline Mandibular plane to Frankfort, ${ }^{\circ}$ & 0.23 & -0.58 & 0.94 & 1.52 & 2.58 & 0.88 & 0.45 & 0.18 & $0.00 *$ \\
\hline Craniomandibular, ${ }^{\circ}$ & -0.21 & -0.96 & 0.59 & 1.61 & 2.45 & 0.65 & 0.52 & $0.02 *$ & $0.00 *$ \\
\hline Facial plane, ${ }^{\circ}$ & -0.72 & -1.03 & -0.88 & 1.28 & 1.73 & 0.89 & $0.01 *$ & $0.00 *$ & $0.00 *$ \\
\hline Facial axis, ${ }^{\circ}$ & -0.12 & -0.05 & -0.85 & 1.21 & 2.23 & 0.82 & 0.64 & 0.89 & $0.00 *$ \\
\hline Condyle axis, ${ }^{\circ}$ & 0.65 & -0.01 & 0.16 & 1.85 & 3.00 & 1.39 & 0.09 & 0.98 & 0.54 \\
\hline Maxillary plane, ${ }^{\circ}$ & 0.06 & 0.25 & 0.06 & 0.93 & 2.19 & 0.62 & 0.74 & 0.49 & 0.58 \\
\hline Occlusal plane to Frankfort, ${ }^{\circ}$ & 0.57 & -1.94 & -1.50 & 2.47 & 4.86 & 1.68 & 0.26 & $0.02 *$ & $0.00 *$ \\
\hline Upper incisor, ${ }^{\circ}$ & 0.05 & 12.42 & 3.91 & 2.36 & 6.50 & 4.05 & 0.91 & $0.00 *$ & $0.00 *$ \\
\hline Lower incisor, ${ }^{\circ}$ & -0.61 & -2.11 & -3.91 & 3.36 & 5.70 & 4.55 & 0.37 & $0.03^{*}$ & $0.00 *$ \\
\hline Interincisor, ${ }^{\circ}$ & 0.54 & -8.26 & 0.00 & 4.13 & 8.25 & 5.57 & 0.52 & $0.00 *$ & 1.00 \\
\hline Convexity, mm & 0.50 & 1.70 & 1.02 & 0.63 & 1.40 & 0.85 & $0.00 *$ & $0.00 *$ & $0.00 *$ \\
\hline $\mathrm{MX}$ position to $\mathrm{Na} / \mathrm{V}, \mathrm{mm}$ & -0.12 & 0.80 & 0.50 & 1.17 & 1.89 & 1.39 & 0.61 & $0.01 *$ & 0.06 \\
\hline $\mathrm{PG}$ to $\mathrm{Na} / \mathrm{V}, \mathrm{mm}$ & -0.94 & -1.54 & -1.63 & 1.79 & 3.28 & 2.92 & $0.01 *$ & $0.01^{*}$ & $0.00 *$ \\
\hline Anterior cranial base, ${ }^{\circ}$ & -1.19 & -1.91 & -0.69 & 0.95 & 1.60 & 0.76 & $0.00 *$ & $0.00 *$ & $0.00 *$ \\
\hline Porion location (Porion-PTV), mm & 0.56 & 0.38 & 0.46 & 0.89 & 1.89 & 0.82 & $0.00 *$ & 0.24 & $0.00 *$ \\
\hline $\mathrm{MxI}$ to $\mathrm{A}-\mathrm{FH}, \mathrm{mm}$ & -0.20 & 3.43 & -1.47 & 1.11 & 2.09 & 2.88 & 0.38 & $0.00 *$ & $0.01 *$ \\
\hline Md I to A-Po, mm & -0.22 & -3.01 & -1.97 & 1.34 & 1.84 & 1.06 & 0.43 & $0.00 *$ & $0.00 *$ \\
\hline Mx 6 to PTV, mm & -1.46 & 0.06 & 0.79 & 1.14 & 2.64 & 1.15 & $0.00 *$ & 0.90 & $0.00 *$ \\
\hline Incisor overjet, $\mathrm{mm}$ & 0.51 & 7.03 & 3.97 & 1.42 & 2.72 & 1.70 & 0.08 & $0.00 *$ & $0.00 *$ \\
\hline Incisor overbite, $\mathrm{mm}$ & 0.22 & 1.34 & 0.81 & 1.86 & 2.54 & 1.33 & 0.57 & $0.00 *$ & $0.00 *$ \\
\hline Molar relation, mm & 0.00 & 4.89 & 4.38 & 1.12 & 2.22 & 1.48 & 1.00 & $0.00 *$ & $0.00 *$ \\
\hline Posterior facial height, $\mathrm{mm}$ & $-2.7 \mathrm{I}$ & -3.22 & -1.57 & 2.02 & 2.37 & 1.39 & 0.00 & $0.00 *$ & $0.00 *$ \\
\hline Midfacial length, mm & -1.33 & -1.73 & -0.18 & 1.60 & 3.30 & 1.90 & 0.00 & 0.00 & 0.61 \\
\hline Mandibular length, $\mathrm{mm}$ & -3.13 & -6.27 & -1.62 & 2.67 & 3.91 & 2.10 & $0.00 *$ & $0.00 *$ & $0.00 *$ \\
\hline Mx/Md difference, $\mathrm{mm}$ & -1.85 & -4.56 & -1.43 & 1.89 & 2.14 & 1.29 & $0.00 *$ & $0.00 *$ & $0.00 *$ \\
\hline Ramus height, mm & -2.28 & -4.19 & -1.32 & 1.83 & 2.49 & 1.31 & $0.00 *$ & $0.00 *$ & $0.00 *$ \\
\hline Corpus length, mm & -2.03 & -1.61 & -1.90 & 1.63 & 2.61 & 1.46 & $0.00 *$ & $0.00 *$ & $0.00 *$ \\
\hline
\end{tabular}

Notes: *Dependent $t$-test; $P$-value $<0.05$. TI: immediately before the insertion of the FRD appliance in fully bonded upper and lower arches, and before any treatment in the TB group. T2: postfunctional appliance removal.

Abbreviations: MX position, A-point to Nasion vertical; Na/V, Nasion vertical; PG, landmark Pogonion; PTV, Pterygoid vertical, a line drawn perpendicular to the Frankfort plane and through point Pterygoid; MxI, Maxillary incisor tip to a perpendicular through A-point to Frankfort horizontal; A-I FH, Perpendicular through A-point to Frankfort horizontal; MdI, Mandibular incisor tip to line A-point to Pogonion; A-Po, Line A-point to Pogonion; SD, standard deviation; CRT, control; TB, Twin Block; FRD, Forsus Fatigue Resistance Device.

\section{Between-group comparisons}

The mean change of the Frankfort to Mandibular plane angle when compared by ANOVA was statistically different between the three groups $(P<0.01)$. However, Tukey analysis showed no evidence that any of the two experimental groups significantly differed from the controls (Table 3).

There was no significant difference between the three groups in many skeletal variables such as cranial base angle, facial depth, facial-axis angle, condyle-axis angle, maxillary plane angle, and mandibular corpus length. The net increases in the mandibular length (Basion-Pogonion) and Ramus height in the FRD group did not differ significantly from the controls. However in the TB group, the increases of both variables were two times larger than in FRD and controls $(P<001)$. The Maxillary position to Nasion/Vertical did not show a significant difference $(P=0.08)$. Midfacial length (Condylion to A-point) was significantly different between TB and FRD $(P=0.04)$; however, neither of the two experimental groups was different from the controls. There is insufficient evidence to support that either of the two appliances had a significant headgear effect.

The mean change of the lower incisor angle was significantly different between the three groups (ANOVA $P=0.042$ ). Statistically significant lower incisors' proclination has occurred in the FRD group when compared with the controls. However, the difference between the FRD and the TB groups was not statistically significant, as confirmed by Tukey HSD test.

\section{Discussion}

This is a retrospective comparative study of two commonly used appliances. The TB and FRD groups showed favorable reduction in skeletal convexity $(1.7 \pm 1.4 \mathrm{~mm}$ and $1.02 \pm 0.85 \mathrm{~mm}$, respectively). This reduction was in 
Table 3 Between-group comparisons of changes between TI and T2

\begin{tabular}{|c|c|c|c|c|c|}
\hline \multirow[t]{2}{*}{ Variable } & \multirow[t]{2}{*}{$\begin{array}{l}F- \\
\text { statistic }\end{array}$} & \multirow[t]{2}{*}{$P$-value* } & \multicolumn{3}{|c|}{$\begin{array}{l}\text { Subsets for alpha } \\
=0.05 * *\end{array}$} \\
\hline & & & $\mathbf{I}$ & 2 & 3 \\
\hline Cranial base, ${ }^{\circ}$ & 0.154 & 0.857 & $\mathrm{C}, \mathrm{F}, \mathrm{T}$ & & \\
\hline $\begin{array}{l}\text { Mandibular plane to } \\
\text { Frankfort, }\end{array}$ & 5.432 & 0.006 & $\mathrm{~T}, \mathrm{C}$ & $\mathrm{C}, \mathrm{F}$ & \\
\hline Craniomandibular, $^{\circ}$ & 6.071 & 0.003 & $\mathrm{~T}, \mathrm{C}$ & $\mathrm{C}, \mathrm{F}$ & \\
\hline Facial plane, ${ }^{\circ}$ & 0.379 & 0.686 & $\mathrm{~T}, \mathrm{~F}, \mathrm{C}$ & & \\
\hline Facial axis, ${ }^{\circ}$ & 2.321 & 0.104 & $\mathrm{~F}, \mathrm{C}, \mathrm{T}$ & & \\
\hline Condyle axis, ${ }^{\circ}$ & 0.643 & 0.528 & $\mathrm{~T}, \mathrm{~F}, \mathrm{C}$ & & \\
\hline Maxillary plane, ${ }^{\circ}$ & 0.165 & 0.849 & $\mathrm{~F}, \mathrm{C}, \mathrm{T}$ & & \\
\hline $\begin{array}{l}\text { Occlusal plane to } \\
\text { Frankfort, }{ }^{\circ}\end{array}$ & 4.143 & 0.019 & $\mathrm{~T}, \mathrm{~F}$ & F, C & \\
\hline Upper incisor, ${ }^{\circ}$ & 52.983 & $<0.001$ & C & $\mathrm{F}$ & $\mathrm{T}$ \\
\hline Lower incisor, ${ }^{\circ}$ & 3.276 & 0.042 & $\mathrm{~F}, \mathrm{~T}$ & $\mathrm{~T}, \mathrm{C}$ & \\
\hline Interincisal, ${ }^{\circ}$ & $19.05 \mid$ & $<0.001$ & $\mathrm{~T}$ & F, C & \\
\hline Convexity, mm & 9.764 & $<0.001$ & $\mathrm{C}, \mathrm{F}$ & $\mathrm{T}$ & \\
\hline $\mathrm{MX}$ position to $\mathrm{Na} / \mathrm{V}, \mathrm{mm}$ & 2.629 & 0.078 & $\mathrm{C}, \mathrm{F}, \mathrm{T}$ & & \\
\hline PG to $\mathrm{Na} / \mathrm{V}, \mathrm{mm}$ & 0.478 & 0.622 & $\mathrm{~F}, \mathrm{~T}, \mathrm{C}$ & & \\
\hline Anterior cranial base, $\mathrm{mm}$ & 8.613 & $<0.001$ & $\mathrm{~T}, \mathrm{C}$ & $\mathrm{C}, \mathrm{F}$ & \\
\hline $\begin{array}{l}\text { Porion location } \\
\text { (Porion-PTV), mm }\end{array}$ & 0.130 & 0.878 & $\mathrm{~T}, \mathrm{~F}, \mathrm{C}$ & & \\
\hline$M x \mid$ to $A-\mid F H, m m$ & 45.449 & $<0.001$ & $\mathrm{~F}, \mathrm{C}$ & $\mathrm{T}$ & \\
\hline Md I to A-Po, mm & 26.328 & $<0.001$ & $\mathrm{~T}$ & $\mathrm{~F}$ & C \\
\hline Mx 6 to PTV, mm & 9.852 & $<0.001$ & C & $\mathrm{T}, \mathrm{F}$ & \\
\hline Incisor overjet, mm & 70.947 & $<0.001$ & C & $\mathrm{F}$ & $\mathrm{T}$ \\
\hline Incisor overbite, mm & 2.308 & 0.105 & $\mathrm{C}, \mathrm{F}, \mathrm{T}$ & & \\
\hline Molar relation, mm & 65.754 & $<0.001$ & $\mathrm{C}$ & $\mathrm{F}, \mathrm{T}$ & \\
\hline Posterior facial height, $\mathrm{mm}$ & 5.721 & 0.005 & $\mathrm{~T}, \mathrm{C}$ & $\mathrm{C}, \mathrm{F}$ & \\
\hline Midfacial length, mm & 3.313 & $0.04 I$ & $\mathrm{~T}, \mathrm{C}$ & $\mathrm{C}, \mathrm{F}$ & \\
\hline Mandibular length, $\mathrm{mm}$ & 19.80 & $<0.001$ & $\mathrm{~T}$ & $\mathrm{C}, \mathrm{F}$ & \\
\hline Mx/Md difference, mm & 28.761 & $<0.001$ & $\mathrm{~T}$ & $\mathrm{C}, \mathrm{F}$ & \\
\hline Ramus height, mm & 18.122 & $<0.001$ & $\mathrm{~T}$ & $\mathrm{C}, \mathrm{F}$ & \\
\hline Corpus length, mm & 0.348 & 0.707 & $\mathrm{C}, \mathrm{F}, \mathrm{T}$ & & \\
\hline
\end{tabular}

Notes: *Analysis of variance test, $P$-value $<0.05$; **Tukey Honestly Significant Differences, homogeneous subset results. TI: immediately before the insertion of the Forsus Fatigue Resistance Device appliance in fully bonded upper and lower arches, and before any treatment in the TB group. T2: postfunctional appliance removal. Abbreviations: C, controls; F, Forsus Fatigue Resistance Device; T, Twin Block; MX position, A-point to Nasion vertical; Na/V , Nasion vertical; PG, landmark Pogonion; PTV, Pterygoid vertical, a line drawn perpendicular to the Frankfort plane and through point Pterygoid; A-I FH, Perpendicular through A-point to Frankfort horizontal; MdI, Mandibular incisor tip to line A-point to Pogonion; A-Po, Line A-point to Pogonion.

agreement with previous $\mathrm{FRD}^{16,18}$ and TB studies ${ }^{21,22}$ in which the A point-Nasion-B point angle angle reduction was used to represent the relative skeletal convexity correction. The difference between the three groups in terms of convexity reduction was highly significant (ANOVA $P<0.001$ ).

There was a significant difference between the three groups in the total mandibular length and maxillary-mandibular (Mx-Md) differential lengths (ANOVA $P<0.001$ ). The total mandibular length increased in the TB group two times more than in the controls $(6.3 \pm 3.9 \mathrm{~mm})$. Similarly, the Mx-Md differential length increased by $4.6 \pm 2.1 \mathrm{~mm}$ in the TB group compared with the controls $(1.8 \pm 1.9 \mathrm{~mm})$. These findings confirm previous investigations $\mathrm{s}^{21,23}$ that suggest a mandibular growth enhancement effect by this appliance. In contrast, the amount of change in the FRD group was not significantly different from in the controls, which parallels the findings of the late puberty FRD group in a previous study ${ }^{18}$ but is in disagreement with another. ${ }^{16}$ The differences between previous reports may not be easily explained because they could be associated with the treatment protocol and duration, wires, and slot dimension; fixed appliance torque differences; ${ }^{16}$ the age factor, ${ }^{18,20}$ and possible different neuromuscular responses..$^{24}$ There was a highly significant increase in the corpus length of all three groups (Student's $t$-test $P<0.001$ ) but no significant difference between them (ANOVA $P=0.70$ ), which suggests it was only a result of the growth effect.

The upper incisors' retroclination was statistically and clinically significant in both experimental groups (Student's $t$-test $P<0.001$ ), with the highest change seen in the TB group. This finding is in contradiction with some previous studies ${ }^{25,26}$ and is in agreement with many others. ${ }^{22,27,28}$ The considerable upper incisors' retroclination may be attributed to the appliance design, particularly when the labial bow is incorporated. ${ }^{22}$ It may also be attributed to the treatment period and treatment modality. In a previous study, ${ }^{23}$ semirapid maxillary expansion and alignment of the upper arch were performed before TB therapy, which may have influenced the amount of retroclination. Pretreatment dentoskeletal characteristics and the variation in appliance-wearing time among patients also have to be taken into consideration. In addition, variability among clinicians adds an operator factor to the effect of this appliance. The upper incisor retroclination in the FRD group was smaller than in the TB group. The presence of fixed brackets on the upper incisors may have limited the amount of retroclination in this group. The $3.9^{\circ}$ retroclination in the FRD group was similar to previous findings, ${ }^{20}$ but it should be noted that direct comparison is not possible because of the different reference lines used in the Clark cephalometric analysis.

At $\mathrm{T} 2$, the lower incisors proclined by an average of $2.1^{\circ}$ and $3.9^{\circ}$ in the TB and FRD groups, respectively, but the difference between the groups was not statistically significant. The lower incisors proclination in the TB group was less than that reported in previous studies. ${ }^{21,22,25,28}$ Many factors that were discussed as possible contributors for the difference in the upper incisors' retroclination are similarly applicable. In some studies, the acrylic of the lower part of the TB appliance was extended to cover the lower incisal edges. This acrylic extension aimed to limit the lower incisors tipping. ${ }^{27,28}$ 
The mean changes in the molar relationship in both groups differed significantly from the controls (4.4 and $4.9 \mathrm{~mm}$ in the FRD and TB groups, respectively; ANOVA $P<0.001$ ). The molar relationship correction was found to be a result of differential anterior/posterior movements of both upper and lower molars in the FRD group with more contribution from lower molar mesialization. ${ }^{29}$

Overjet correction was significantly different between the three groups (ANOVA $P<0.001$ ). The overjet reduction in the FRD group was about half of that in the TB group, which could be partially explained by the small initial overjet, which was 7.1 and $11.3 \mathrm{~mm}$ in the FRD and TB groups, respectively. A similar finding was reported in a recent investigation, ${ }^{29}$ where there was slightly larger overjet correction with TB ( $\sim 6 \mathrm{~mm})$ than FRD $(5 \mathrm{~mm})$, but interestingly, the authors found no statistically significant difference between the two appliances in the percentage change of overjet. Patient compliance with the use of the TB removable appliance did not seem to play a major rule because the appliance was able to normalize the class II malocclusion into class I.

This study has several limitations. The baseline differences in some variables between the groups might have introduced susceptibility bias. The results are applicable for short-term observation periods and may differ if a long-term follow-up is carried out. The retrospective nature of the study was also another limitation. A randomized clinical trial is always recommended, as it has the highest level of evidence when investigating the efficacy of orthodontic appliances. However, it alone is not enough for a comprehensive understanding of the functional orthodontic treatment. An investigation of three-dimensional soft tissue changes and temporomandibular changes/remodeling during and after treatment completion in prospective tomographic studies is recommended.

\section{Conclusion}

The FRD and TB are effective in the treatment of patients with class II malocclusion. Both appliances were able to induce favorable changes in the sagittal relation, but the type of change differed significantly between the groups. The TB induced mandibular skeletal correction with much less influence on the maxilla. The FRD induced dentoalveolar changes, and the contribution to the final overjet correction was a result of an equal combination of upper incisor retroclination and lower incisor proclination.

\section{Acknowledgment}

We thank Robert Dunford for his help with the statistical analysis.

\section{Disclosure}

The authors report no conflicts of interest in this work.

\section{References}

1. Tulloch JF, Medland W, Tuncay OC. Methods used to evaluate growth modification in Class II malocclusion. Am J Orthod Dentofacial Orthop. 1990;98(4):340-347.

2. Proffit WR, Fields HW, Sarver DM. Contemporary Orthodontics. 4th ed. St Louis, MO: Mosby Elsevier; 2007.

3. Chadwick SM, Banks P, Wright JL. The use of myofunctional appliances in the UK: a survey of British orthodontists. Dent Update. 1998;25(7):302-308.

4. Clark WJ. The twin block traction technique. Eur J Orthod. 1982;4(2):129-138

5. Clark WJ. The twin block technique. A functional orthopedic appliance system. Am J Orthod Dentofacial Orthop. 1988;93(1):1-18.

6. Clark WJ. Twin Block Functional Therapy: Applications in Dentofacial Orthopaedics. 2nd ed. Edinburgh: Mosby; 2002.

7. Baccetti T, Franchi L, Toth LR, McNamara JA Jr. Treatment timing for Twin-block therapy. Am J Orthod Dentofacial Orthop. 2000;118(2):159-170.

8. O'Brien K, Wright J, Conboy F, et al. Effectiveness of early orthodontic treatment with the Twin-block appliance: a multicenter, randomized, controlled trial. Part 2: Psychosocial effects. Am J Orthod Dentofacial Orthop. 2003;124(5):488-494, discussion 494-495.

9. McSherry PF, Bradley H. Class II correction-reducing patient compliance: a review of the available techniques. J Orthod. 2000;27(3): 219-225.

10. Stromeyer EL, Caruso JM, DeVincenzo JP. A cephalometric study of the Class II correction effects of the Eureka Spring. Angle Orthod. 2002;72(3):203-210.

11. West RP. The adjustable bite corrector. J Clin Orthod. 1995;29(10): 650-657.

12. Flores-Mir C, Barnett G, Higgins DW, Heo G, Major PW. Short-term skeletal and dental effects of the Xbow appliance as measured on lateral cephalograms. Am J Orthod Dentofacial Orthop. 2009;136(6):822-832.

13. Rothenberg J, Campbell ES, Nanda R. Class II correction with the Twin Force Bite Corrector. J Clin Orthod. 2004;38(4):232-240.

14. Vogt W. The Forsus Fatigue Resistant Device. J Clin Orthod. 2006;40(6):368-377, quiz 358.

15. Jones G, Buschang PH, Kim KB, Oliver DR. Class II non-extraction patients treated with the Forsus Fatigue Resistant Device versus intermaxillary elastics. Angle Orthod. 2008;78(2):332-338.

16. Franchi L, Alvetro L, Giuntini V, Masucci C, Defraia E, Baccetti T. Effectiveness of comprehensive fixed appliance treatment used with the Forsus Fatigue Resistant Device in Class II patients. Angle Orthod. 2011;81(4):678-683.

17. Karacay S, Akin E, Olmez H, Gurton AU, Sagdic D. Forsus Nitinol Flat Spring and Jasper Jumper corrections of Class II division 1 malocclusions. Angle Orthod. 2006;76(4):666-672.

18. Aras A, Ada E, Saracoğlu H, Gezer NS, Aras I. Comparison of treatments with the Forsus fatigue resistant device in relation to skeletal maturity: a cephalometric and magnetic resonance imaging study. Am J Orthod Dentofacial Orthop. 2011;140(5):616-625.

19. Gunay EA, Arun T, Nalbantgil D. Evaluation of the Immediate Dentofacial Changes in Late Adolescent Patients Treated with the Forsus(TM) FRD. Eur J Dent. 2011;5(4):423-432.

20. Oztoprak MO, Nalbantgil D, Uyanlar A, Arun T. A cephalometric comparative study of class II correction with Sabbagh Universal Spring (SUS(2)) and Forsus FRD appliances. Eur J Dent. 2012;6(3):302-310.

21. Tümer N, Gültan AS. Comparison of the effects of monoblock and twin-block appliances on the skeletal and dentoalveolar structures. $\mathrm{Am}$ J Orthod Dentofacial Orthop. 1999;116(4):460-468.

22. Lund DI, Sandler PJ. The effects of Twin Blocks: a prospective controlled study. Am J Orthod Dentofacial Orthop. 1998;113(1):104-110. 
23. Trenouth MJ. Cephalometric evaluation of the Twin-block appliance in the treatment of Class II Division 1 malocclusion with matched normative growth data. Am J Orthod Dentofacial Orthop. 2000;117(1):54-59.

24. Sood S, Kharbanda OP, Duggal R, Sood M, Gulati S. Muscle response during treatment of Class II Division 1 malocclusion with Forsus Fatigue Resistant Device. J Clin Pediatr Dent. 2011;35(3):331-338.

25. Mills CM, McCulloch KJ. Treatment effects of the twin block appliance: a cephalometric study. Am J Orthod Dentofacial Orthop. 1998;114(1):15-24.

26. Mills CM, McCulloch KJ. Posttreatment changes after successful correction of Class II malocclusions with the twin block appliance. Am J Orthod Dentofacial Orthop. 2000;118(1):24-33.
27. Sidlauskas A. Clinical effectiveness of the Twin block appliance in the treatment of Class II Division 1 malocclusion. Stomatologija. 2005;7(1):7-10.

28. Sidlauskas A. The effects of the Twin-block appliance treatment on the skeletal and dentolaveolar changes in Class II Division 1 malocclusion. Medicina (Kaunas). 2005;41(5):392-400.

29. Mahamad IK, Neela PK, Mascarenhas R, Husain A. A comparision of Twin-block and Forsus (FRD) functional appliance - a cephalometric study. Int J Orthod Milwaukee. 2012;23(3):49-58.

\section{Publish your work in this journal}

Clinical, Cosmetic and Investigational Dentistry is an international, peer-reviewed, open access, online journal focusing on the latest clinical and experimental research in dentistry with specific emphasis on cosmetic interventions. Innovative developments in dental materials, techniques and devices that improve outcomes and patient satisfaction and preference will be highlighted. The manuscript management system is completely online and includes a very quick and fair peerreview system, which is all easy to use. Visit http://www.dovepress. com/testimonials.php to read real quotes from published authors.

Submit your manuscript here: http://www.dovepress.com/clinical-cosmetic-and-investigational-dentistry-journal 